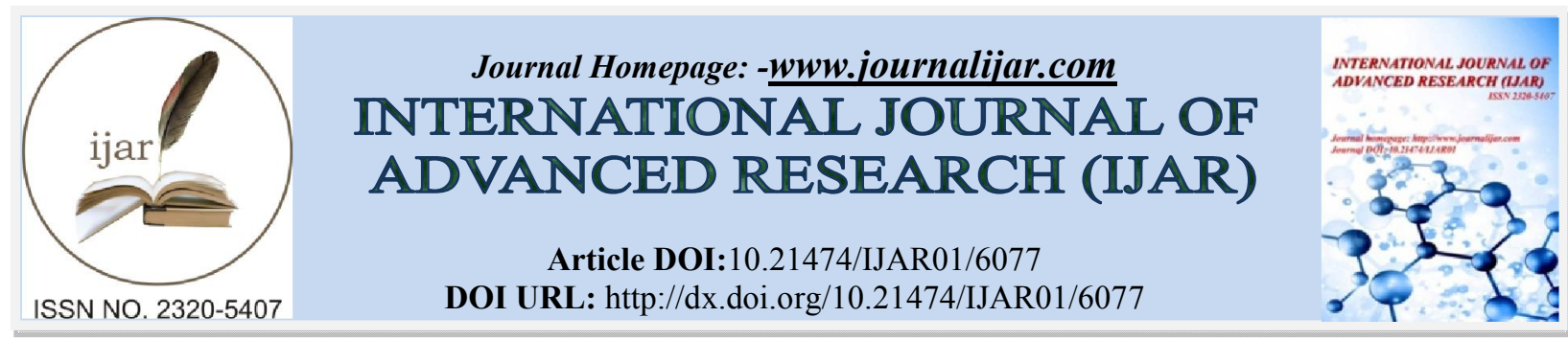

RESEARCH ARTICLE

\title{
REMINERALIZING AND COLOR RETRIEVAL EFFICACY OF DIFFERENT NANO-APATITE MATERIALS ON HUMAN ENAMEL WHITE SPOT LESIONS: AN IN-VITRO COMPARATIVE STUDY
}

Omaima H. Ghallab" and "Dina M. Abdelkhalik

1. Associate professor of Operative Dentistry, Faculty of Dentistry, Ain- Shams University, Cairo, Egypt.

2. Lecturer of Oral Biology, Faculty of Dentistry Ain-Shams University, Cairo, Egypt.

\section{Manuscript Info}

Manuscript History

Received: 16 October 2017

Final Accepted: 18 November 2017

Published: December 2017

Key words:-

Remineralization; white spot lesions;

Nano-Apatite; Enamel;

Spectrophotometer; Mineral content

\section{Abstract}

This study aimed to evaluate and compare the mineral acquisition and color regain potency of synthetic nano hydroxyapatite, nano fluoroappatite, natural nano hydroxyapatite and human enamel nano powder on enamel white spot lesions.

Materials and Methods: 24 human premolars were used. $\mathrm{Ca}$ and $\mathrm{P}$ mineral content by EDAX, CIE L* $\mathrm{a}^{*} \mathrm{~b}^{*}$ and $\Delta \mathrm{E}^{*}$ color parameters by spectrophotometer were measured at three levels of the study. At each level, ESEM evaluated the surface morphology of the samples.

Results: Ca wt \% revealed a significant loss after demineralization for $\mathrm{CG}$ and significant increase for RG1 and RG3 following the remineralization. $\mathrm{P}$ wt \% showed a significant increase in RG2. Color measurement showed significant degrees of color change $\Delta \mathrm{E}$, after demineralization, as well as $\mathrm{L}^{*} \mathrm{a}^{*}$ and $\mathrm{b}^{*}$ values that showed some degree of color recovery after remineralization. ESEM showed recovery of enamel surface among the remineralized groups.

Conclusions: 1-Quantitative element analysis by EDAX is accurate, simplified technique to assess changes in mineral content.

2-All the nano-sized apatite remineralizing materials showed the capability to remineralize the artificial white spot lesions. 3-The remineralizing efficacy of all the nano-sized apatite materials was the same. 4-Color retrieval was efficient to some extent among materials.

Copy Right, IJAR, 2017,. All rights reserved.

\section{Introduction:-}

Enamel is the hardest calcified tissue in the human body. Its unique ectodermal origin, tightly packed crystalline arrangement and exceptional non collagenous proteins provide it with distinguished properties (Bath-Balogh et al., 2006). It is composed of crystalline latticework of calcium (Ca) Phosphate (P) mineral called hydroxyapatite (HA) (Denewar et al., 2014). Water and organic matter as proteins and lipids are the rest. As it covers the outer most layer of the crown, it withstands many challenges as forces and acids from diet and bacterial biofilm (Jindal et al., 2015).

One of the earliest microscopic signs of demineralization under intact enamel is white spots leading to cavitations which are the terminal stage of progressive mineral loss. White spots result from organic acids that have etched the enamel layer and created porosities of the sub surface crystalline structure, that change the refractive index (color changes) of the normally translucent enamel, as optical scattering was enhanced (Kim et al., 2012) .Silverstone 
etal.,1975 classified the acid etching of enamel into five patterns; Type I represents dissolution of the prism cores, Type II affected the periphery, Type III showed a mixture of I\& II, a pitted enamel surface is Type IV and finally Type V leaves a smooth surface. These lesions can be present in both deciduous and permanent teeth and appear as whiteness of the enamel surface, which is rejected esthetically from the patients necessitating noninvasive or minimally invasive interactions.

White spot lesions are often seen when orthodontic brackets are removed or may result from heavy plaque accumulation, inadequate oral home care routines, and a high sugar or acid content diet (Vick et al., 2007) and (Singh et al., 2016). These porosities allow for better penetration of the ions required for remineralization. The different treatment modalities; bleaching/deproteination or combined approach bleaching and etching, microabrasion, and resin infiltration were performed (Kim et al., 2012) and (Tyagi et al., 2013).

Conditionally, remineralization may become the predominant process, thus leading to lesion repair, while if the biolfilm accumulation and the frequent sugar exposure are not controlled, enamel mineral loss definitely occurs (Kielbassa et al., 2009).

A natural phenomenon of enamel remineralization can occur by $(\mathrm{Ca})$ and $(\mathrm{P})$ found in the biofilm fluid or by direct action of salivary $\mathrm{Ca}$ and $\mathrm{P}$ (Ten Cate et al., 2008), but it may take a long time that reaches to 5-12 years, until complete remineralization of the surfaces as well as deeper areas of white spot lesions. So, it needs the use of external remineralizing agents for mineral regain and better esthetics in a shorter time (Singh et al, 2016). If saliva has lesser ionic mineral product than the solubility mineral product of enamel, the altered enamel surface can be subjected to many adverse effects, especially where remineralization is not reversed within time (Bhusari\& Sharma, 2017).

One of the most traditional widely used remineralizing agents is fluoride (Xiang-Ge et al., 2010). Among other remineralizing agents of early caries lesions launched after year 2000, include casein phosphopeptide stabilized amorphous calcium phosphate (CPP-ACP; Recaldent ${ }^{\mathrm{TM}}$ ), the second is an unstabilized amorphous calcium phosphate (ACP, Enamelon ${ }^{\mathrm{TM}}$ ), and the third is a bioactive glass containing calcium sodium phosphosilicate (NovaMin ${ }^{\mathrm{TM}}$ ) (Reynolds, 2008). These new materials contain calcium and phosphate ions as the strategy for aided remineralization is to have ions directly delivered to where needed most and their effect is based on enhancement of the natural capacity of saliva to remineralize mineral loss (Cury\&Tenuta, 2009).

Apatite is a group of phosphate minerals, usually referring to hydroxylapatite, fluorapatite and chloroapatite, with high concentrations of $\mathrm{OH}^{-}, \mathrm{F}-$ and $\mathrm{Cl}-$ ions, respectively, in the crystal. The formula of which is written as $\mathrm{Ca}_{10}\left(\mathrm{PO}_{4}\right)_{6}(\mathrm{OH}, \mathrm{F}, \mathrm{Cl})_{2}$. Nano-hydroxyapatite (NHA) is a biocompatible compound with high affinity for tooth enamel. NHA particles morphologically resemble dental enamel apatite crystals (Haghgoo et al., 2016)

Hydroxyappatite is the main inorganic component in bones and teeth. It can be synthetically prepared or derived from natural sources (as bovine bones and teeth or coralline fluroappatites), both of which are widely used. Being biocompatible with an osteoinductive property, synthetic HA are comparable to natural HA, but because of their high cost and time -consuming preparation procedures, natural appatites are more commonly used (Lu et al., 2007). According to (Zhang et al., 2014), flourides can remineralize enamel through replacing the $\mathrm{OH}^{-}$ions in the directive lattice of hydroxyapatite crystals (HAP). These ions attract Calcuim (Ca) ions, followed by Phosphorous (P) ions resulting in a new mineral formulation (flouroapatite). Fluoroapatites are the reason why white spot lesions maintain its chemical and mechanical properties with an intact surface. These fluoroapatites are less soluble in acids than hydroxyapatites, this also happens because saliva remineralizes the surface (Kim et al., 2012) and (Machale et al., 2013). Similarly, in the present study, human enamel was used in a nano form to simulate the previously used apatites.

Nanotechnology is the creation of functional materials through control of matter on the nanometer scale. Currently, this technology is experiencing many potential applications in dentistry and has motivated mimicking of the nanostructural features of natural human enamel and development of bio-inspired strategies for remineralization and caries therapy, respectively (Hannig and Hannig, 2012). Recently, treatment of early caries lesions by the application of various types of nano-sized apatite or calcium carbonate has received considerable attention (Huang et al., 2011). A dentifrice containing $1 \%$ nano-sized amorphous calcium carbonate particles (several tens to 
hundreds of $\mathrm{nm}$ ), applied twice a day over 20 days, showed statistically significant remineralization of artificial carious lesions (Nakashima et al., 2009).

Remineralization by nanotechnology can repair the porous structure and be considered an ideal non invasive approach. When $\mathrm{Ca}$ and $\mathrm{P}$ ions returned to the demineralized enamel surface causing its reconstitution, light scattering decreases which influences the overall color perception of the tooth (Kim et al., 2012). The color of natural teeth can be measured by CIE L* $a^{*} b^{*}$ system. It consists of three segments; $L^{*}$ represents the lightness, while $a^{*}$ represents red-green color axis and $b^{*}$ represents yellow-blue color axis. The values of the tristimulus in CIE L* $a^{*} b^{*}$ system is closely matched with those three colors ( red, green and blue) to which the human vision is sensitive , according to trichromatic theory of color vision ( Kim et al., 2012) and (Carneriro et al., 2013).

The present work aimed to evaluate and compare, the remineralizing (mineral acquisition) and color regain potency of synthetic nano HA, nanoFluoroappatite, natural nano HA and human enamel nano powder on enamel white spot lesions.

This was achieved through:

1. Sur face morpholoy of enamel by Environmental Scanning Electron Microscopy (ESEM).

2. Surface $\mathrm{Ca}$ and $\mathrm{P}$ content analysis of enamel by energy dispersive $\mathrm{X}$-ray micro- analyzer (EDAX).

3. Spectrophotometer for detection of color changes.

The tested null hypotheses were that:

First, there was a difference in the remineralizing potency of the different Nano-sized apatite materials used in the present study. Second, color retrieval would be achieved using nano- sized apatites.

\section{Materials and Methods:}

\section{1-Collection of human teeth:}

Twenty four upper sound human premolars recently extracted for orthodontic reasons from patients of age group (18-25) years, also five impacted wisdom teeth were used in the present study. The teeth were obtained from the Oral and Maxillofacial Department, Faculty of Dentistry, Ain- Shams University. A patient's signed consent was obtained upon extraction according to the Committee of Ethics, Faculty of Dentistry, Ain- Shams University. Teeth were cleaned from the blood and soft tissues, disinfected and stored in fresh, renewed deionized water at $4^{\circ} \mathrm{C}(\mathrm{Kim}$ et al., 2012) till the beginning of the experimental procedures not more than one month. The premolar teeth were examined under the light stereomicroscope (SZ-PT OLYMPUS-JAPAN) to exclude teeth with cracks, abrasions and decay on the buccal surfaces. There was standardization through the use of the same tooth as a control to be investigated before and after treatment.

\section{2-Preparation of the enamel samples:}

Every premolar was marked with a fixed number throughout the study from (1-24);

(1-6) CG1, (7-12) CG2, (13-18) CG3 and (19-24) CG4, where $(n=6)$. The crowns of the human premolars were coated with two layers of acid resistant nail varnish (Maybellene, France) to prevent the leakage of the used chemicals to the covered parts, leaving only the middle third of the buccal surface of enamel exposed with an area of $(2 \times 4 \mathrm{~mm})$ (Kim et al., 2012). All samples were first evaluated regarding their enamel surface morphology using ESEM, surface mineral content using EDAX and color by spectrophotometer at baseline (control group) (CG). The enamel of the wisdom impacted molars was cut by using diamond disc (Edental Golden SAW, Switzerland) under copious water coolant in the Department of Oral Biology, Faculty of Dentistry, Ain-Shams University for preparation of the nano-sized enamel powder.

\section{3-Creation of enamel white spot lesions:}

Demineralizing solution composed of: $2.2 \mathrm{ml}$ Calcium Chloride $\left(\mathrm{CaCl}_{2}\right), 0.05$ moles per litre (M) Acetic Acid $\left(\mathrm{CH}_{3} \mathrm{COOH}\right)$ and $2.2 \mathrm{ml}$ Sodium Dihydrogen Phosphate $\left(\mathrm{NaH}_{2} \mathrm{PO}_{4}\right)$. The $\mathrm{pH}$ of the demineralizing solution was adjusted to $\mathrm{pH}=4.4$, by the addition of Potassium Hydroxide $(\mathrm{KOH})$ was prepared in MORGAN Specialty Chemicals Company (JAS-ANZ, ISO 22000- 1st Industrial Region, Al-Obour) (Ten Cate and Duijsters, 1982). Then, all enamel samples of human premolars were subjected to artificial non- cavitated white spots, by immersing them individually, into the demineralizing solution $(10 \mathrm{ml} /$ tooth for 96 hours at room temperature) (Tschoppea et 
al., 2011) and after lesions creation, they were carefully rinsed with deionized water to remove all remnants of the demineralizing solution and again evaluated for ESEM, EDAX and color change (Demineralized group) (DG1, 2, 3, 4).

\section{4-Preparation of the nanoparticles powders: \\ Three of the reminrealizing materials (Synthetic nanohydroxyappatite, Natural nanohydroxyappatite, nanofluoroappatite, Wards Company, USA) and the natural human enamel obtained from the previously extracted wisdom teeth were subjected to nano grinding. This process was performed at the Metallurgical Development, Research Centre (Helwan, Giza Egypt).}

This was done by ultra-fine dry grinding in a planetary mill. A planetary micro mill Fritch model 4, with two Canisters supplied from (FRITSCH Company, Germany) as shown in figure (1). The canister volume is $250 \mathrm{ml}$, agate balls with $2 \mathrm{~mm}$ size was used. A representative sample about 10 gram and 100 gram of agate balls was put in the canister. The mill was started at $250 \mathrm{rpm}$ for 30 hours grinding time. After finishing, the mill was discharged and the product was sieved for removing the balls. The particle size (less than $100 \mathrm{~nm}$ ) of the ultra fine powder was obtained using BT 2001 laser particle size analyzer.

\section{5-Preparation of the treatment remineralizing gels:}

At the National Research Centre (Department of pharmacology, Dokki ,Giza, Egypt), a suspension of each appatite was prepared through mixing $110 \mathrm{mg}$ of the test material in double distilled water and completing the volume to $10 \mathrm{ml}$ with continuous stirring by means of a magnetic stirrer. The gel was prepared through the addition of sodium carboxy methyl cellulose (CMC), $500 \mathrm{mg}$ the gelling agent; sodium chloride previously prepared under continuous stirring at $1000 \mathrm{rpm}(5 \% \mathrm{w} / \mathrm{v})$. CMC is known to be used at high concentrations to produce gels that can be used as a base for applications and pastes. The formed gels were kept at $8^{\circ} \mathrm{C}$ for 24 hours before use (Rowe et al., 2009).

\section{6-Grouping of demineralized enamel samples:}

The demineralized enamel samples with white spot lesions were divided into four equal groups (six teeth each) according to the treatment remineralizing gel used as follows:

Group (1): Treated with Synthetic nanohydroxyappatite. RG1

Group (2): Treated with Nano Fluoroappatiteappatite. RG2

Group (3): Treated with Natural nanohydroxyappatite. RG3

Group (4): Treated with Enamel nano powder. RG4

\section{7-Remineralizing protocols application:}

Enamel samples with white spot lesions from each group were subsequently subjected to the remineralizing treatment gel previously mentioned. The gels were applied with a flexible, disposable microfiber brush (Voco, Cuxhaven, Germany) twice a day (10 minutes each) for 20 days (Hannig and Hannig, 2010). Pea- sized amount of gel was smeared over the exposed demineralized enamel surface area of interest. After each application, the tooth was carefully rinsed with deionized water to ensure complete removal of the gel remnants, and then restored in newly poured deionized water for subsequent applications. Then, the enamel samples were evaluated for ESEM, EDAX and color change (Remineralized group) (RG).

\section{8-ESEM evaluation of surface enamel samples morphology:}

Each enamel sample was evaluated three times; before white spots formation (control) (sound enamel) at base line, after white spot formation (demineralized enamel) and after treatment (remineralized enamel). The buccal surface of each premolar was adjusted on the holder to examine the middle third of enamel. No surface treatment or film deposition as gold or carbon was performed on the enamel surfaces facilitating reusing the same samples again at different treatment intervals. Enamel surface morphologyy was evaluated using ESEM Model Quanta 250 FEG (Field Emission Gun) attached with EDX Unit (Energy Dispersive X-ray Analyses), with accelerating voltage 30 K.V., magnification14x up to 1000000 and resolution for Gun.1n) in The Egyptian Mineral Resources Authority ,Central Laboratories Sector, Giza, Egypt). Electronmicrographs were obtained at 30 kilovoltage (KV) using secondary electron live fiber detection (LFD) detector under the magnification of (1000x-5000x) with a spot size (4.7 - $5.3 \mathrm{~nm}$ ) for each sample. 


\section{9-Quantitative analysis of surface mineral content of enamel samples by EDAX:}

Using Energy Dispersive X-ray Analyzer (EDAX) with S- UTW detector (EDAX Inc., Mahwah, NJ, USA) to chemically analyze and measure calcium $(\mathrm{Ca})$ and phosphorus $(\mathrm{P})$ weight $\%$ of each enamel sample three times; before white spots formation (control) (sound enamel) at base line, after white spot formation (demineralized enamel) and after treatment (remineralized enamel). Each enamel sample was placed under vacuum and excited to a higher energy state with an electron beam. As the electrons of each element falls back down to its original energy state, it emits x-ray energy at different specified wave length. Each element was identified by its known wave length on the $\mathrm{x}$-axis represented by a peak and the intensity of the peak on the y-axis determines the amount of the element. These minerals were expressed as a weight percentage.

\section{0-Assessment of color of enamel samples by spectrophotometer:}

CIE L* $a^{*} b^{*}$ system was used for determination of the color of the enamel samples three times; before white spots formation (control) (sound enamel) at base line, after white spot formation (demineralized enamel) and finally after remineralization treatment (remineralized enamel).

The enamel samples were removed from the deionized water, dried with blotting paper and immediately placed in Spectrophotometer which is the most widely used instrument for color measuring. It is designed to measure the ratio of the light reflected from a sample to that reflected from a reference white across the visible spectrum at intervals of $1,5,10$, or $20 \mathrm{~nm}$. The results are expressed by spectral reflectance function. It is, simply, consisting of a light source, a monochromator, and a detector. Its geometry of illumination (light source) and viewing (detector) should conform to one of the four CIE recommendations, 45/Normal (45/0), Normal/45 (0/45), Diffuse/Normal (d/0), and Normal/Diffuse (0/d).

The apparatus used in measurements is Cary 5000 Spectrophotometer provided from Agilent Technologies (USA). Agilent Cary $5000 \mathrm{UV}$-Vis-NIR spectrophotometer is manufactured according to a quality management system certified to ISO 9001.

It is a double beam direct ratio recording system. It consists of the photometer unit and a pc computer. The optical system of the photometer unit includes a double monochromator of grating to grating type. The light beam from a tungsten halogen lamp after passing through the double monochromator (to be monochromatic) is chopped by a chopper mirror into the sample beam and reference beam, and then passes through the sample compartment to the detector. The light beam is detected by a photomultiplier which is sensitive to the visible/ultraviolet region.

The micro-computer in the spectrophotometer works to control the light source lighting, light source switching, filter switching, grating switching, wavelength scanning motor and detector switching, according to the commands from the data station. The wavelength scans in these measurements were carried out from $380 \mathrm{~nm}$ to $780 \mathrm{~nm}$.

Integrating spheres measure diffuse reflectance and transmittance factors, commonly called reflectance and transmittance. The relative spectral reflectance (transmittance) is defined as the ratio of the flux reflected (transmitted) by the specimen to that of a standard surface under identical geometrical and spectral conditions. For transmittance the standard surface is air, and for reflectance the standard surface is a secondary white standard calibrated relative to the perfectly reflecting diffuser. Because of the geometry of the integrating sphere, it has the ability to collect most reflected or transmitted radiation, remove any directional preferences, and present an integrated signal to the detector.

\section{Reflectance measurement:-}

CIE L*a*b* color values for each sample were then calculated from the diffuse reflectance data by using the color software application which is available through Cary WinUv instrument.

\section{CIE L*a*b* color space:}

$\mathrm{L}^{*}$ is a measure of the Lightness of an object, ranging from 0 (Black) to 100 (White).

$a^{*}$ is a measure of redness $(a>0)$ or greenness $(a<0)$.

$b^{*}$ is a measure of yellowness $(b>0)$ or blueness $(b<0)$.

The $\mathrm{L}^{*} \mathrm{a} * \mathrm{~b} *$ color space is shown in Figure (2). Along the vertical axis (the neutral axis), between black $(\mathrm{L}=0)$ and white $(\mathrm{L}=100)$ is a continuous range of gray shades. 


\section{Color difference determination:}

The degree of color difference between the compared colors is expressed in $\Delta \mathrm{E}^{*}$ units. The total color difference, according to $\mathrm{L}^{*}, \mathrm{a}^{*}, \mathrm{~b}^{*}$ coordinates, is calculated as shown in the equation: $\Delta E^{*}=\left[\left(\Delta L^{*}\right)^{2}\left(\Delta a^{*}\right)^{2}\left(\Delta b^{*}\right)^{2}\right]^{1 / 2}$

\section{Statistical Analysis:}

The mean and standard deviation values were calculated for each group in each test. Data were explored for normality using Kolmogorov-Smirnov and Shapiro-Wilk tests and showed parametric (normal) distribution.

One-way ANOVA followed by Tukey post hoc test was used to compare between more than two groups in nonrelated samples. Repeated measure ANOVA was used to compare between more than two groups in related samples. The significance level was set at $\mathrm{P} \leq 0.05$. Statistical analysis was performed with IBM ${ }^{\circledR}$ SPSS ${ }^{\circledR}$ Statistics Version 20 for Windows.

\section{Results:}

I-ESEM Results of Surface Micro-morphology of Enamel Surfaces; Sound (control), Demineralized and Remineralized: Represented by figures $(3-9)$.

\section{II-EDAX (Quantitative Enamel Surface Mineral Content Analysis):}

I) Calcium (wt \%) Mineral Content Results: as shown in table (1):

a) Group1 (Synthetic Nano Apatite):

After demineralization, there was a statistically significant decrease in $\mathrm{Ca} \mathrm{wt} \%$ comared to the control (non treated enamel) where $(p=0.017)$. While after remineralization, there was a statistically significant increase in $\mathrm{Ca} \mathrm{wt} \%$, compared to after demineralization $(p=0.018)$, which also was not statistically significant compared to the control where $(p=0.633)$.

b) Group 2 (Nano Fluoro Apatite):

There was no statistically significant difference between (Control), (After demineralization) and (After remineralization) regarding tha $\mathrm{Ca} w \mathrm{t} \%$ where $(p=0.217)$.

c) Group 3 (Nano Natural Apatite):

There was a statistically significant difference between (Control), (After Demineralization) and (After remineralization) where $(p=0.008)$.

After remineralization there was a statistically significant increase in $\mathrm{Ca} w \mathrm{t} \%$ compared to after demineralization where $(p=0.004)$.

No statistically significant difference was found between the control and after remineralization..

d) Group 4 (Nano-sized Enamel):

There was no statistically significant difference between (Control), (After demineralization) and (After remineralization) where $(p=0.162)$.

\section{II) Phosphorus wt\% Mineral Content Results: as shown in table (2):}

\section{a) Group1 (Synthetic Nano Apatite):}

There was no statistically significant difference between (Control), (After demineralization) and (After remineralization) regarding the $\mathrm{P}$ wt $\%$ where $(p=0.452)$.

b) Group2 (Nano Fluoro Apatite):

There was a statistically significant difference between (Control), (After demineralization) and (After remineralization) where $(p=0.022)$.

(After remineralization), there was a statistically significant increase in $\mathrm{P} w \mathrm{t} \%$ compared to (After demineralization) where $(p=0.002)$.

c) Group3 (Nano Natural Apatite):

There was no statistically significant difference between (Control), (After demineralization) and (After remineralization) regarding $\mathrm{P} \mathrm{wt} \%$ where $(p=0.093)$. 


\section{d) Group4 (Nano-sized Enamel):}

There was no statistically significant difference between (Control), (After demineralization) and (After remineralization) regarding $\mathrm{P} w \mathrm{wt} \%$ where $(p=0.399)$.

Regarding the remineralizing efficacy among the different nano apatite materials, there was no statistically significant difference between (Group1), (Group2), (Group3) and (Group4) for Ca wt $\%$ where $(p=0.752)$ and for $\mathrm{P}$ wt $\%$ where $(p=0.050)$ as shown in tables (1) and (2).

\section{III) Spectrophotometer Results of Color Parameters:}

\section{I-(L*) Color Parameter: as shown in table (3):}

For all groups 1, 2, 3 and 4, (After demineralization), there was a statistically significant increase in lightness parameter compared to (Control) and (After remineralization) where $(p<0.001)$.

A statistically significant increase was found (After remineralization) compared to (Control) where $(p<0.001)$, which was also statistically significant less than (After demineralization).

There was no statistically significant difference between (Group1), (Group2), (Group3) and (Group4) regarding the change in lightness parameter where $(p=0.357)$.

II-(a*) Color Parameter results: as shown in table (4):

For all groups 1, 2, 3 and 4, there was a statistically significant decrease in a* value (red-green) for (After demineralization) compared to (Control) and (After remineralization).

(After remineralization) there was a statistically significant increase in $\mathrm{a}^{*}$ value (red-green) compared to (After demineralization) and also statistically significant lower than (Control).

Among the remineralizing groups, group (1) showed a higher statistically significant difference regarding the change in $\mathrm{a}^{*}$ value compared to group (4), and non statistically significant different compared to group (2) and (3).

\section{III-(b*) Color Parameter: as shown in table (5):}

For all groups 1, 2, 3 and 4, there was a statistically significant decrease in $b^{*}$ value (yellow-blue) for (After demineralization) compared to (Control) and (After remineralization).

(After remineralization) there was a statistically significant increase in $b^{*}$ value (yellow-blue) compared to (After demineralization) and also statistically significant lower than (Control).

Among the remineralizing groups, they showed a non statistically significant difference regarding the change in $\mathrm{b}^{*}$ value.

IV- $\left(\Delta \mathbf{E}^{*}\right)$ color change parameter: as shown in table (6):

For all groups 1, 2, 3 and 4, there was a statistically significant difference between (Control and after demineralization), (Control and after remineralization) and (After demineralization and after remineralization) where $(p<0.001)$.

A statistically higher significant difference of $\Delta \mathrm{E}^{*}$ color change was found between (Control and after demineralization) that was clinically detectable (more than 3.3) and (Control and after remineralization) which was clinically undetectable (less than 3.3) and $\Delta \mathrm{E}^{*}$ color change of (After demineralization and After remineralization) which was clinically not detectable for group (1) and clinically detectable for the groups (2), (3), and (4). of (Control and after remineralization) and (After Demineralization and after remineralization) where $(p<0.001)$. Also, a statistically significant difference was found between (Control and after demineralization) and (After Demineralization and after remineralization) where $(p<0.001)$.

Among the groups (1-4) the change in $\Delta \mathrm{E}^{*}$ color change between (Control and after remineralization) was statistically significant where $(p<0.001)$. 


\section{Discussion:-}

Enamel repair or rehardening is used as synonyms of remineralization, which is defined as the reconstruction of enamel surface by redeposition of minerals mainly, $\mathrm{Ca}$ and $\mathrm{P}$ after they were lost by demineralization, sub micrometer or enamel erosions, which depleted the tooth surface from its mineral content. This dynamic physicochemical process takes place when oral bacteria form a biofilm over the tooth surfaces (Tyagi et al., 2013) (Shett et al., 2014) (Gorseta et al., 2015) (Jindal et al., 2015) (Abou Neel et al., 2016).

In the present study, nano-apatite materials were used as one of the most recent biomimetic approaches for healing of initial sub micrometer enamel erosions. In vitro data of previous literature reported that, the use of apatite with dimensions adapted to the scale of sub micrometer and nano-sized defects with dimension of a length (60-80nm) and a diameter of $(10-20 \mathrm{~nm})$ caused by demineralization of the natural apatite crystals, could extremely enhance the repair of enamel demineralization (Hannig\&Hannig, 2010), that's why the particle size used in this work was less than $100 \mathrm{~nm}$. It was declared that, the remineralization influence increased if the particle size of (HA) is reduced down to the nano scale range. Actually, this was because the interaction of nano particles with enamel and dentin tissues is more pronounced as the surface area to volume ratio increased (Selivany\& AL-Hano, 2015). This was achieved through the merits of the nano structured materials of being kinetically protected because of their nano size and remains secured even in unsaturated conditions. In addition to, HA exhibits excellent non toxic, bioactive, biocompatible properties with lack of inflammatory and immunological responses (Reynolds et al., 2008).

HA represents the main ingredient of enamel surface that affords its brightness, white appearance and eliminates the diffused light reflection by plugging the pores of the external tooth surface (Selivany\& AL-Hano, 2015). The concentration of $\mathrm{Ca}$ and $\mathrm{P}$ in this layer of enamel was notified to be harder than the inner surface, considering the importance of relevant investigation of this layer and evaluation of any alterations that may exist (Sandeep et al., 2015), according to previous data, the outermost enamel surface was the area of interest.

The results of this study reported a statistically significant increase in the difference between the control group CG and the demineralized group DG regarding Cawt\% by EDAX, as shown in table (1). The minerals eluted outside the crystals from the interior of enamel as an outcome of acid penetration of the demineralizing solution (Hayashi et al., 2016). These findings were confirmed by ESEM, which differs from the conventional SEM in that no sample preparation is needed allowing the reuse of same samples. In the control group, the enamel surface exhibited uniform aprismatic surface with perikymata ridges and few fine scratches (fig.3) while, in the demineralized group, the electronmicrographs represented various degrees of demineralization in the form of exposure of prismatic enamel and cracked aprismatic enamel and also disorientation of enamel crystals with erosion of prism cores and appearance of crater shaped cavities as shown in fig $(4,5)$. These findings come in accordance with( Galil\& Wright,1979) who stated that exposure of the prismatic layer showed type I etching pattern because bicuspids extracted for orthodontic reasons which had perikymata showed type I etching pattern. Also, (Patil et al., 2013) observed that surface cracks, discontinuities and crater-shaped cavities demonstrated a more vigorous etching pattern.

Traditionally, the previous mineral density measuring methods were destructive for the specimens; as chemical analysis of a micro-sample or by contact micro radiography and polarizing microscopy (Zhi et al., 2013). Recently, EDAX facilitates quantitative measurement of the surface minerals alteration accurately and in an easy manner without devastation of the sample which aid in reusing them again (Majithia et al., 2016).

The results of EDAX regarding the Cawt\% content analysis, in the remineralized group as shown in table (1) where, there was an effective remineralizing potential represented in high statistically significant values of the four nanosized apatite remineralizing materials tested in this study, while there was no statistically significant difference between them. So, according to these findings, the first null hypothesis was rejected. This was in accordance with previous studies that supported the use of nano-HACs in biomineralization of initial enamel erosions (Hannig\&Hannig, 2010) (Wu et al., 2013) (Mielczarek\&Michalik, 2014) who reported significant decrease in surface roughness of enamel lesions treated with nano-HA dentifrice. These results were confirmed with ESEM morphology of the remineralized enamel white spot lesions, which showed, uniform enamel surface and obliteration of prism cores in RG1 (fig.6), while in RG2, RG3 circumscription of prism periphery and partial narrowing of prism cores with a uniform layer obliterating the rod ends was observed (fig.7, 8). In RG4, enamel recovered a fish scale appearance (fig.8) which confirmed the remineralizing potency of the used material. 
On the other hand, $\mathrm{P}$ wt $\%$ revealed no significant difference among all groups except RG2 which demonstrated a significant increase compared to the demineralized group as shown in table (2).

This observation might be attributed to the ability of nano-HA to integrate into the enamel carious lesion surface structure. Findings in the present study come in accordance with (Coceska et al., 2015), concluded that, the treatment with a tooth- paste containing HA left the enamel surface normal with deposits of HA. (Mohant et al., 2014) reported the increase in mean $\mathrm{Ca} / \mathrm{P}$ ratio after remineralizaion the enamel lesions with fluoride-enhanced $\mathrm{HA}$ gel. (Sandeep et al., 2015) confirmed the highest values of surface microhardness of enamel specimens treated with HA cream which was statistically significant compared to the control non treated group. These results demonstrated an increase in mineral gain. (Comar et al., 2013) recommended the regular daily use of nano HA products as it might diffuse inward gradually toward the deep areas of white spot lesions and deposite during long term remineralization. HA works by stuffing the nano sized pores of incipient carious lesions that it acts as a template in repair process by sustained attraction of large amount of $\mathrm{Ca}$ and $\mathrm{P}$ ions from the oral fluids into the lesion, thus assisting HA crystal growth (Bennett, 2015).

The effect of nano-HA on demineralized enamel may be due to the physically powerful of this nano particles adsorption to the acidic etched enamel surface under in-vitro conditions (Hannig\&Hannig, 2010). It was obvious that, the effect of the remineralizing $\mathrm{HA}$ strongly depends on the $\mathrm{pH}$ during its application. Under neutral $\mathrm{pH}$, full remineralization and enamel reconstruction may not be achievable. While under acidic conditions (as in this work) $(\mathrm{pH}=4.4)$, nano sized HA can effectively increase the depth of penetration and extent of remineralization of an incipient artificial white spot lesions (Tschoppeetal, 2011) and (Huang et al., 2011). This was attributed to the charge adsorption effect which was created between the free $\mathrm{Ca}$ and $\mathrm{P}$ ions in the remineralizing agents and the negative/positive charge domain on etched enamel surfaces (Wu et al., 2013). Even that, some preliminary evidence advocated the use of nano sized HA in sports drinks as an additive, may intensify the remineralization potential and the resistance to demineralization of incipient enamel lesions (Huang et al., 2009).

In RG 1, synthetic nanoapatite (SA) and its resembling GR 3, natural nanoapatite revealed a high statistical significant effect on Cawt \% gained compared to DG and non statistical significant difference with CG as declared in table (1), This might be attributed to the chemical bond between (SA) and the surface of prismatic HA enamel through formation of a surface coating (carbonate-HA coating). (Roveri et al., 2009) suggested that, the treatment of demineralized enamel with synthetic HA just for 10 minutes, provided remineralization.

On the other hand, the redeposit ion of $\mathrm{Ca}$ and $\mathrm{P}$ into the enamel surface may develop a highly mineralized external layer. This zone might be hypothesized to have bi-functional effects; the first is to reduce the demineralization process, through inhibiting diffusion of acids into deeper enamel areas. Worthy, the second, it could block the diffusion of mineral ions to reconstitute the sub surface enamel re-crystallization (Comar et al., 2013). So, it is valuable to investigate whether this superficial layer can inhibit the caries process progression in-vivo and be sufficient for caries treatment (Mielczarek\&Michalik, 2014).

Identification of color of natural tooth may be affected by some variables such as the non homogenous layers of the curved surfaces, variations in specimen thickness, degree of surface smoothness, degree of crystallization, prism orientation, translucency, gloss and backing conditions. The reflection of incident light in addition to the influence of scattered light inside the enamel and underlying dentin structures determined the final perceived color of the natural tooth (Kim et al., 2012).

In this study, spectrophotometer was used to determine the color of the natural teeth as it is reliable, objective, quantifiable and more rapidly obtainable (Kim et al., 2005). It measures the amount of light reflected from the object over the full spectral wave length, which allows providing more systematic and precise measurements than colorimeters (Da Silva et al., 2008). For natural morphology, the enamel surfaces in the present study were not ground, also the position of the samples at every color measurement was fixed by putting fixed marks on the lateral sides of the samples.

The results of the artificially created white spot lesions reported high significance increase in L* values (lightness) compared to $\mathrm{CG}$ and RG as shown in table (3). Also, the change in a* values was statistically significant compared to $\mathrm{CG}$ and $\mathrm{RG}$ which reported change in color to redness $\left(-\mathrm{a}^{*}\right)$, but after remineralization the change in color parameter was decreased in redness toward the green color $\left(+\mathrm{a}^{*}\right)$ as declared in table (4), except for RG 4, the 
change was increase in greenness, as the mean base line of the enamel samples was $(-0.2 \pm 0.3)$ for CG and became ($1.25 \pm 0.25)$ for $\mathrm{DG}$, after remineralization, slight decrease in greenness obtained $(-0.63 \pm 0.25)$. While for $b^{*}$ values, all results for the CG were in yellowness region, which became lower statistically significant after demineralization for all groups (decrease in yellowness) and after remineralization in all RGs the values appeared (increase in yellowness), but this change was still statistically significant lower than CGs table (5).

The changes in DG were related to the caries activity and increased roughnesses of the enamel surfaces after exit of minerals due to the action of the demineralizing solution. Thus, pores were increased and the light scattering (which depends on the surface texture) was magnified (Browning et al., 2012). This was confirmed by EDAX analysis of tooth minerals which were reduced after demineralization.

The color change is expressed as $\Delta \mathrm{E}^{*}$ table (6), which represents the sum of color change of the three parameters $\mathrm{L}^{*}, \mathrm{a}^{*}$ and $\mathrm{b}^{*}$. In addition, it is calculated mathematically, so it is more meaningful than the individual three parameters values (Okubo et al., 1998). There are different thresholds of $\Delta \mathrm{E}^{*}$ above which, the change in color is detected by the human eyes and unaccepted clinically. In previous literature, it was reported the values of $\Delta \mathrm{E}^{*}$ in the range (2-3) were visible to the naked eye and still clinically accepted. While $\Delta \mathrm{E}^{*}$ was considered clinically unacceptable if the values reached $\geq 3.3$ units (Kim et al., 2004). In the present study, $\Delta \mathrm{E}$ color change values between $\mathrm{CG}$ and DG all were above (3.3 units), which indicated unaccepted color change. On the other hand, $\Delta \mathrm{E}^{*}$ color change between $C G$ and $R G$ was lesser than (3.3) for all types of nanoapatite remineralizing materials as shown in table (6). These obtained outcomes refer to the powerful color reversal of the nanoapatite remineralizing materials used in this study, especially for the synthetic nano apatite $\mathrm{RG}$, which advocated $\Delta \mathrm{E}$ value $(2.84 \pm 0.45)$ between DG and RG within accepted range in color change. Based on these findings, the second null hypothesis was accepted. This was in accordance with (Mielczarek\&Michalik, 2014) and (Coceska et al., 2015) who reported that, the demineralized surfaces changed to others smoother and shiner because of intergration of nano HA into the enamel lesions. Also, it was in agreement with (Browning et al., 2012) who concluded a decrease in surface irregularities and increase the surface gloss after treating enamel with nano HA and nano carbonate apatite, suggesting that irregularities that appeared after bleaching noticeably recovered by the remineralization effect.

Repair of white spot lesions is not only mineral deposition on the enamel surfaces, but also sub surface crystal repair. The variations of repair efficacy may be related to the deposition of the nano-sized HA crystals with different orientation reflecting altered optical properties. Moreover, some enlarged pores may not be fully refilled as a result of limited time of remineralization process, which might need a longer time to be completed (Kim et al., 2012). In addition to, the outer most layer of enamel surface is often aprismatic due to absence of prisms. This layer has a dense arrangement, high mineral content and less permeable gradually worn off by the effect of mastication forces but still remained protected areas. This finding may explain the variant degree of demineralization among the samples that appeared in ESEM micrographs, which in turn influenced the degree of remineralization and color retrieval potency (Ceci et al., 2015).

It was important to notify that, the outcome findings of this research may not fully represent the in-vivo conditions in the oral cavity, which may challenge the repair process.

So, within the limitations of this in-vitro study the following conclusions could be drawn:

1-Quantitative element analysis by EDAX was found to be an accurate and simplified technique to assess change in mineral content of enamel surfaces.

2-All the nano-sized apatite remineralizing materials used in this study showed the capability to remineralize the artificial white spot lesions to a certain degree in the outlined remineralizing time.

3-The remineralizing efficacy of all the nano-sized apatite remineralizing materials used in this study was to be the same.

4-Color retrieval was efficient to some extent among all the nano-sized apatite remineralizing materials used in this study especially it appeared more pronounced with the nano synthetic apatite material. 
Table (1):-The mean, standard deviation (SD) values of Calcium (Ca) wt\% of different groups:

\begin{tabular}{|c|c|c|c|c|c|c|c|}
\hline \multirow[t]{3}{*}{ Variables } & \multicolumn{7}{|c|}{ Calcium (Ca) wt\% } \\
\hline & \multicolumn{2}{|l|}{ Control } & \multicolumn{2}{|c|}{$\begin{array}{l}\text { After } \\
\text { demineralization }\end{array}$} & \multicolumn{2}{|c|}{ After remineralization } & \multirow[t]{2}{*}{ p-value } \\
\hline & Mean & SD & Mean & SD & Mean & SD & \\
\hline Group 1 & $48.36^{\mathrm{aA}}$ & 2.16 & $37.69^{\mathrm{aB}}$ & 4.36 & $47.23^{\mathrm{aA}}$ & 3.62 & $0.006 *$ \\
\hline Group 2 & $46.07^{\mathrm{abA}}$ & 4.52 & $41.77^{\mathrm{aA}}$ & 5.11 & $45.32^{\mathrm{aA}}$ & 3.14 & $0.271 \mathrm{~ns}$ \\
\hline Group 3 & $40.28^{\mathrm{bAB}}$ & 4.34 & $37.06^{\mathrm{aB}}$ & 4.67 & $46.71^{\mathrm{aA}}$ & 2.47 & $0.008 *$ \\
\hline Group 4 & $42.35^{\mathrm{abA}}$ & 3.34 & $41.53^{\mathrm{aA}}$ & 4.87 & $47.38^{\mathrm{aA}}$ & 3.79 & $0.162 n s$ \\
\hline p-value & \multicolumn{2}{|l|}{$0.015 *$} & \multicolumn{2}{|l|}{$0.291 \mathrm{~ns}$} & \multicolumn{2}{|l|}{$0.752 \mathrm{~ns}$} & \\
\hline
\end{tabular}

Means with different small letters in the same column indicate statistically significance difference. Means with different capital letters in the same row indicate statistically significance difference. *; significant $(p \leq 0.05)$ ns; non-significant $(p>0.05)$

Table (2):-The mean, standard deviation (SD) values of Phosphorus (P) wt\% of different groups:

\begin{tabular}{|c|c|c|c|c|c|c|c|}
\hline \multirow[t]{3}{*}{ Variables } & \multicolumn{7}{|c|}{ Phosphorus (P) wt\% } \\
\hline & \multicolumn{2}{|l|}{ Control } & \multicolumn{2}{|c|}{ After demineralization } & \multicolumn{2}{|c|}{ After remineralization } & \multirow[b]{2}{*}{ p-value } \\
\hline & Mean & SD & Mean & SD & Mean & SD & \\
\hline Group 1 & $18.88^{\mathrm{aA}}$ & 3.38 & $18.45^{\mathrm{a} A}$ & 2.30 & $20.34^{\mathrm{aA}}$ & 0.50 & $0.452 \mathrm{~ns}$ \\
\hline Group 2 & $18.92^{\mathrm{aAB}}$ & 0.75 & $18.32^{\mathrm{aB}}$ & 0.64 & $19.56^{\mathrm{aA}}$ & 0.70 & $0.022 *$ \\
\hline Group 3 & $17.99^{\mathrm{a} A}$ & 1.59 & $17.51^{\mathrm{a} A}$ & 1.58 & $19.78^{\mathrm{aA}}$ & 0.23 & $0.093 n s$ \\
\hline Group 4 & $18.80^{\mathrm{a} A}$ & 0.81 & $18.22^{\mathrm{a} A}$ & 2.26 & $19.50^{\mathrm{a} A}$ & 0.34 & $0.399 \mathrm{~ns}$ \\
\hline p-value & $0.855 n s$ & & $0.850 \mathrm{~ns}$ & & $0.050 \mathrm{~ns}$ & & \\
\hline
\end{tabular}

Means with different small letters in the same column indicate statistically significance difference. Means with different capital

letters in the same row indicate statistically significance difference. *; significant $(\mathrm{p} \leq 0.05)$ ns; non-significant $(\mathrm{p}>0.05)$

Table (3):-The mean, standard deviation (SD) values of $\left(\mathrm{L}^{*}\right)$ color parameter of different groups:

\begin{tabular}{|c|c|c|c|c|c|c|c|}
\hline \multirow[t]{3}{*}{ Variables } & \multicolumn{7}{|l|}{$\left(L^{*}\right)$} \\
\hline & \multicolumn{2}{|c|}{ Control } & \multicolumn{2}{|c|}{ After demineralization } & \multicolumn{2}{|c|}{ After remineralization } & \multirow[b]{2}{*}{ p-value } \\
\hline & Mean & SD & Mean & SD & Mean & SD & \\
\hline Group 1 & $67.38^{\mathrm{aC}}$ & 1.17 & $70.81^{\mathrm{aA}}$ & 1.40 & $68.60^{\mathrm{aB}}$ & 1.13 & $<0.001 *$ \\
\hline Group 2 & $69.68^{\mathrm{aC}}$ & 2.24 & $73.57^{\mathrm{aA}}$ & 2.75 & $70.43^{\mathrm{aB}}$ & 2.20 & $<0.001 *$ \\
\hline Group 3 & $67.13^{\mathrm{aC}}$ & 1.90 & $70.95^{\mathrm{aA}}$ & 1.88 & $68.26^{\mathrm{aB}}$ & 1.98 & $<0.001 *$ \\
\hline Group 4 & $67.12^{\mathrm{aC}}$ & 3.16 & $71.59^{\mathrm{aA}}$ & 3.40 & $68.79^{\mathrm{aB}}$ & 3.10 & $<0.001 *$ \\
\hline p-value & \multicolumn{2}{|l|}{$0.169 n s$} & \multicolumn{2}{|l|}{$0.225 \mathrm{~ns}$} & \multicolumn{2}{|l|}{$0.357 \mathrm{~ns}$} & \\
\hline
\end{tabular}

Means with different small letters in the same column indicate statistically significance difference. Means with different capital letters in the same row indicate statistically significance difference. *; significant $(p \leq 0.05)$, ns; non-significant $(p>0.05)$

Table (4):-The mean, standard deviation (SD) values of $\left(a^{*}\right)$ color parameter of different groups:

\begin{tabular}{|c|c|c|c|c|c|c|c|}
\hline \multirow[t]{3}{*}{ Variables } & \multicolumn{7}{|l|}{$\left(a^{*}\right)$} \\
\hline & \multicolumn{2}{|l|}{ Control } & \multicolumn{2}{|c|}{ After demineralization } & \multicolumn{2}{|c|}{ After remineralization } & \multirow[b]{2}{*}{ p-value } \\
\hline & Mean & SD & Mean & SD & Mean & SD & \\
\hline Group 1 & $0.69^{\mathrm{aA}}$ & 0.67 & $-0.40^{\mathrm{aC}}$ & 0.55 & $0.55^{\mathrm{aB}}$ & 0.71 & $<0.001 *$ \\
\hline Group 2 & $0.23^{\mathrm{a} A}$ & 0.22 & $-0.78^{\mathrm{aC}}$ & 0.40 & $0.03^{\mathrm{abB}}$ & 0.21 & $<0.001 *$ \\
\hline Group 3 & $0.35^{\mathrm{aA}}$ & 0.80 & $-0.67^{\mathrm{aC}}$ & 0.70 & $0.24^{\mathrm{abB}}$ & 0.79 & $<0.001^{*}$ \\
\hline Group 4 & $-0.21^{\mathrm{aA}}$ & 0.30 & $-1.25^{\mathrm{aC}}$ & 0.25 & $-0.63^{\mathrm{cB}}$ & 0.25 & $<0.001 *$ \\
\hline p-value & \multicolumn{2}{|l|}{ 0.073ns } & \multicolumn{2}{|c|}{$0.056 n s$} & \multicolumn{2}{|l|}{ 0.011* } & \\
\hline
\end{tabular}

Means with different small letters in the same column indicate statistically significance difference. Means with different capital letters in the same row indicate statistically significance difference. *; significant $(p \leq 0.05)$ ns; non-significant $(p>0.05)$ 
Table (5): The mean, standard deviation (SD) values of $\left(b^{*}\right)$ color parameter of different groups:

\begin{tabular}{|c|c|c|c|c|c|c|c|}
\hline \multirow[t]{3}{*}{ Variables } & \multicolumn{7}{|l|}{$\left(b^{*}\right)$} \\
\hline & \multicolumn{2}{|c|}{ Control } & \multicolumn{2}{|c|}{ After demineralization } & \multicolumn{2}{|c|}{ After remineralization } & \multirow[b]{2}{*}{ p-value } \\
\hline & Mean & SD & Mean & SD & Mean & SD & \\
\hline Group 1 & $5.62^{\mathrm{aA}}$ & 2.27 & $3.11^{\mathrm{aC}}$ & 2.40 & $4.54^{\mathrm{aB}}$ & 2.21 & $<0.001 *$ \\
\hline Group 2 & $6.19^{\mathrm{aA}}$ & 1.01 & $3.38^{\mathrm{aC}}$ & 0.92 & $5.33^{\mathrm{aB}}$ & 1.08 & $<0.001 *$ \\
\hline Group 3 & $6.66^{\mathrm{aA}}$ & 2.44 & $3.75^{\mathrm{aC}}$ & 2.10 & $6.16^{\mathrm{aB}}$ & 2.49 & $<0.001 *$ \\
\hline Group 4 & $6.57^{\mathrm{aA}}$ & 2.96 & $3.85^{\mathrm{aC}}$ & 3.27 & $5.50^{\mathrm{aB}}$ & 2.94 & $<0.001 *$ \\
\hline p-value & \multicolumn{2}{|c|}{$0.857 n s$} & \multicolumn{2}{|c|}{$0.942 n s$} & \multicolumn{2}{|c|}{$0.683 n s$} & \\
\hline
\end{tabular}

Means with different small letters in the same column indicate statistically significance difference. Means with different capital letters in the same row indicate statistically significance difference. ${ }^{*}$; significant $(\mathrm{p} \leq 0.05)$ ns; non-significant $(\mathrm{p}>0.05)$

Table (6):-The mean, standard deviation (SD) values of $\left(\Delta \mathrm{E}^{*}\right)$ color change parameter of different groups:

\begin{tabular}{|c|c|c|c|c|c|c|c|}
\hline \multirow[t]{3}{*}{ Variables } & \multicolumn{7}{|l|}{$\left(\Delta \mathbf{E}^{*}\right)$} \\
\hline & \multicolumn{2}{|c|}{ Control and after demineralization } & \multicolumn{2}{|c|}{$\begin{array}{l}\text { Control and after } \\
\text { remineralization }\end{array}$} & \multicolumn{2}{|c|}{$\begin{array}{l}\text { After } \\
\text { demineralization and } \\
\text { after remineralization }\end{array}$} & \multirow[t]{2}{*}{ p-value } \\
\hline & Mean & $\mathrm{SD}$ & Mean & SD & Mean & SD & \\
\hline Group 1 & $4.42^{\mathrm{a} A}$ & 0.42 & $1.65^{\mathrm{bC}}$ & 0.08 & $2.84^{\mathrm{aB}}$ & 0.45 & $<0.001 *$ \\
\hline Group 2 & $4.91^{\mathrm{aA}}$ & 0.73 & $1.18^{\mathrm{cC}}$ & 0.14 & $3.81^{\mathrm{aB}}$ & 0.79 & $<0.001 *$ \\
\hline Group 3 & $4.93^{\mathrm{aA}}$ & 0.55 & $1.25^{\mathrm{cC}}$ & 0.18 & $3.77^{\mathrm{aB}}$ & 0.61 & $<0.001 *$ \\
\hline Group 4 & $5.37^{\mathrm{aA}}$ & 0.55 & $2.03^{\mathrm{aC}}$ & 0.16 & $3.38^{\mathrm{aB}}$ & 0.62 & $<0.001 *$ \\
\hline$p$-value & \multicolumn{2}{|c|}{$0.069 \mathrm{~ns}$} & \multicolumn{2}{|c|}{$<0.001 *$} & \multicolumn{2}{|c|}{$0.052 \mathrm{~ns}$} & \\
\hline
\end{tabular}

Means with different small letters in the same column indicate statistically significance difference. Means with different capital letters in the same row indicate statistically significance difference. *; significant $(\mathrm{p} \leq 0.05) \quad$ ns; non-significant $(\mathrm{p}>0.05)$

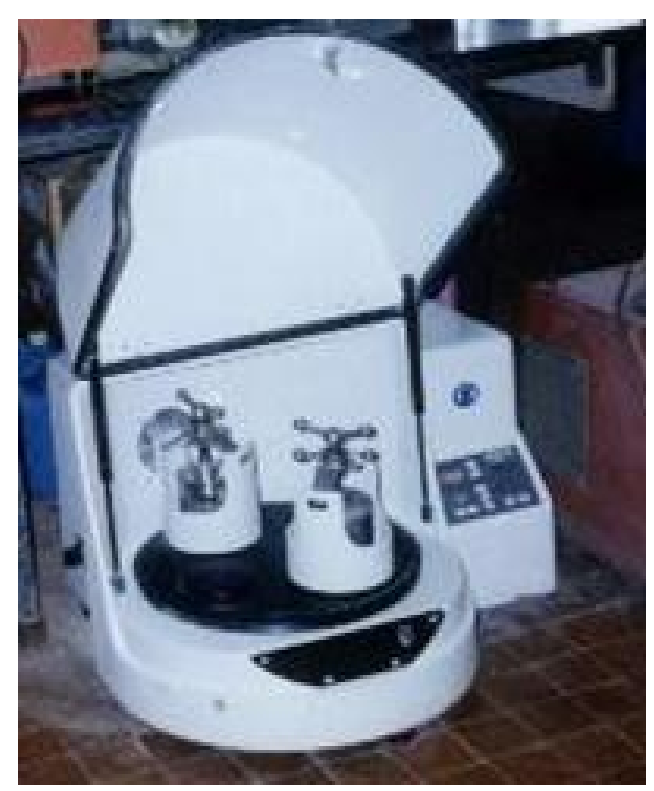

Figure (1):- "FRITSCH" Planetary Ball Mill 


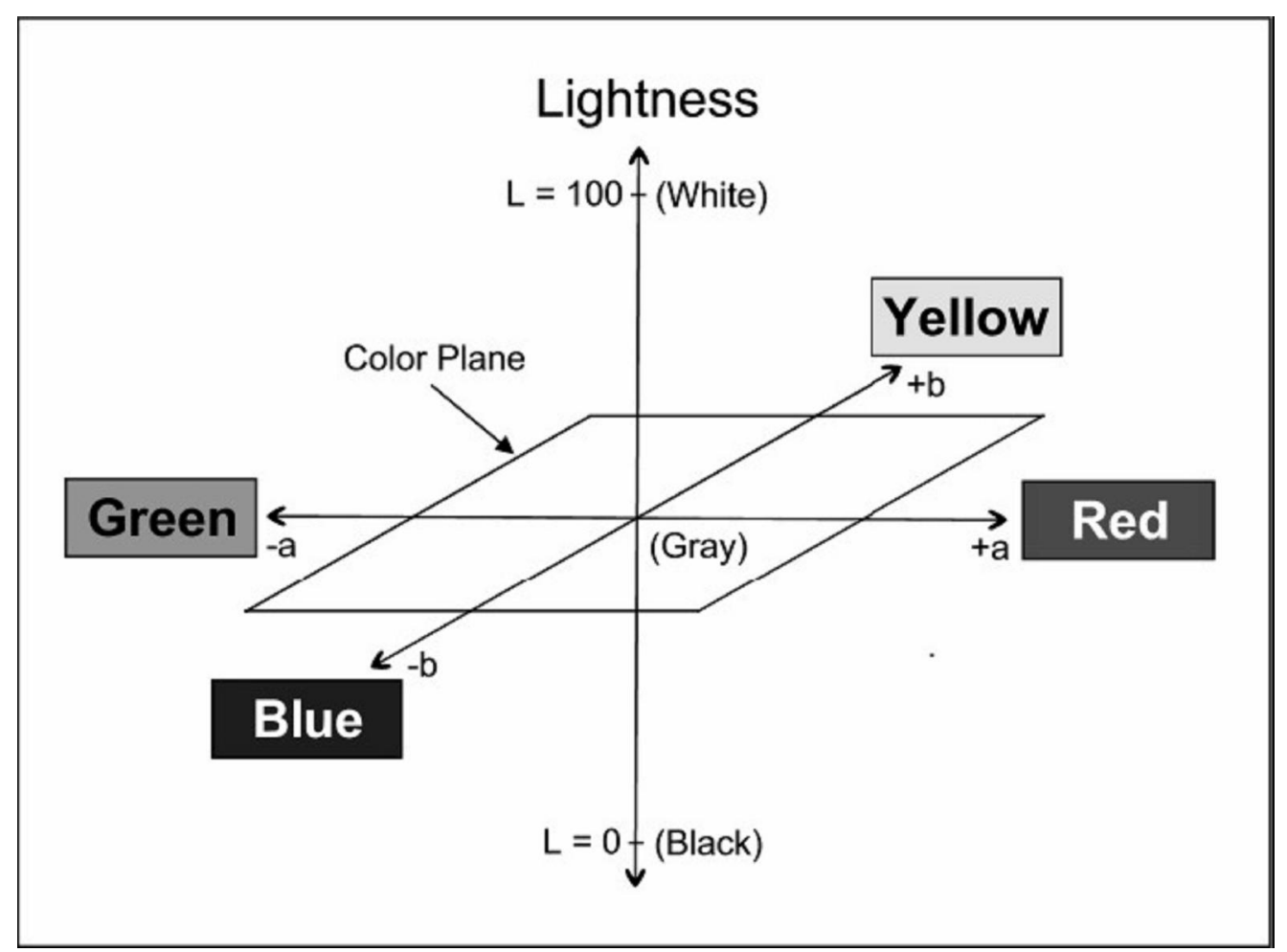

Figure (2):-Schematic Diagram of L*a*b* color space

\section{Control Group (Non-treated enamel)-Base Line:}

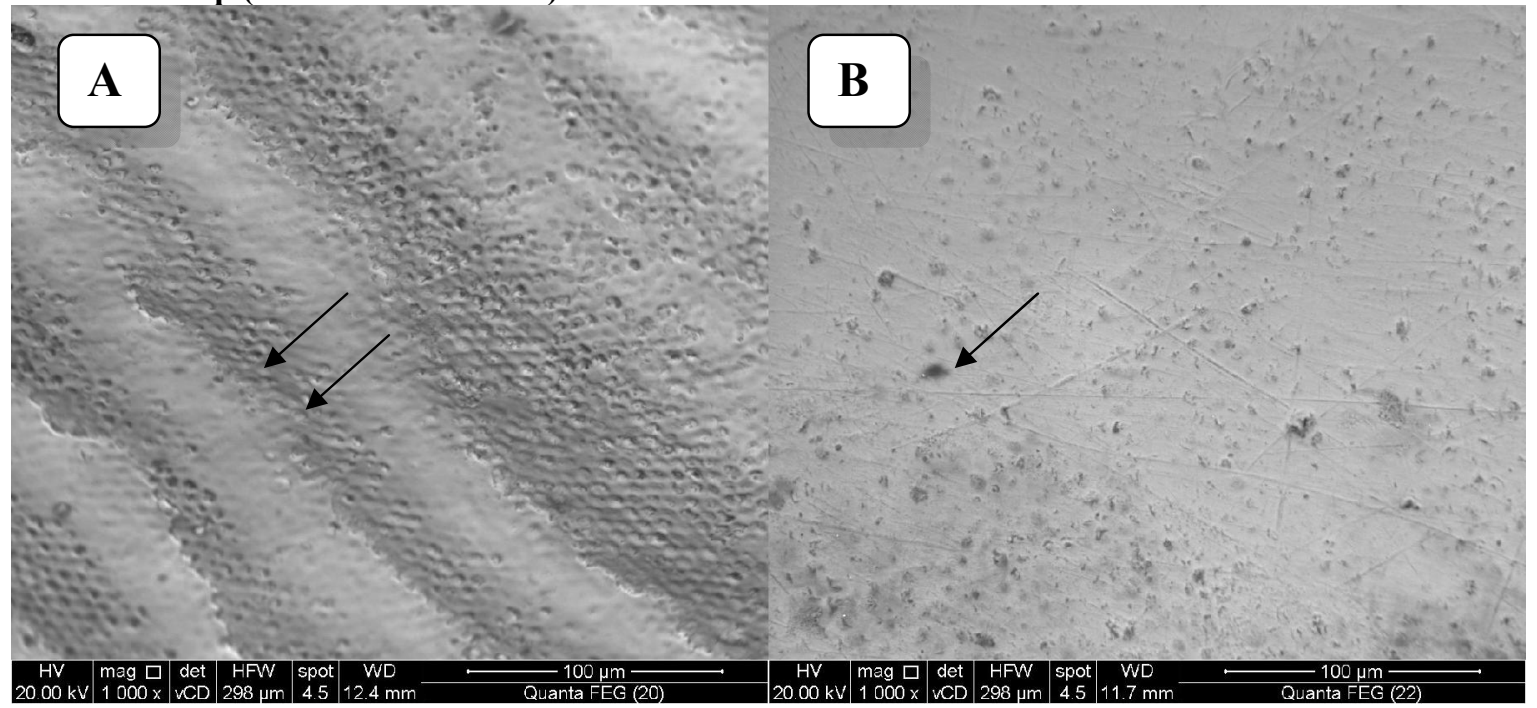

Figure (3) :- (A) ESEM micrograph of control enamel surface (1000x) showing perikymata ridges (black arrows) over a uniform aprismatic surface. (B) Rod ends (black arrow) and few fine scratches. 
Demineralized Enamel (White Spot Lesions):

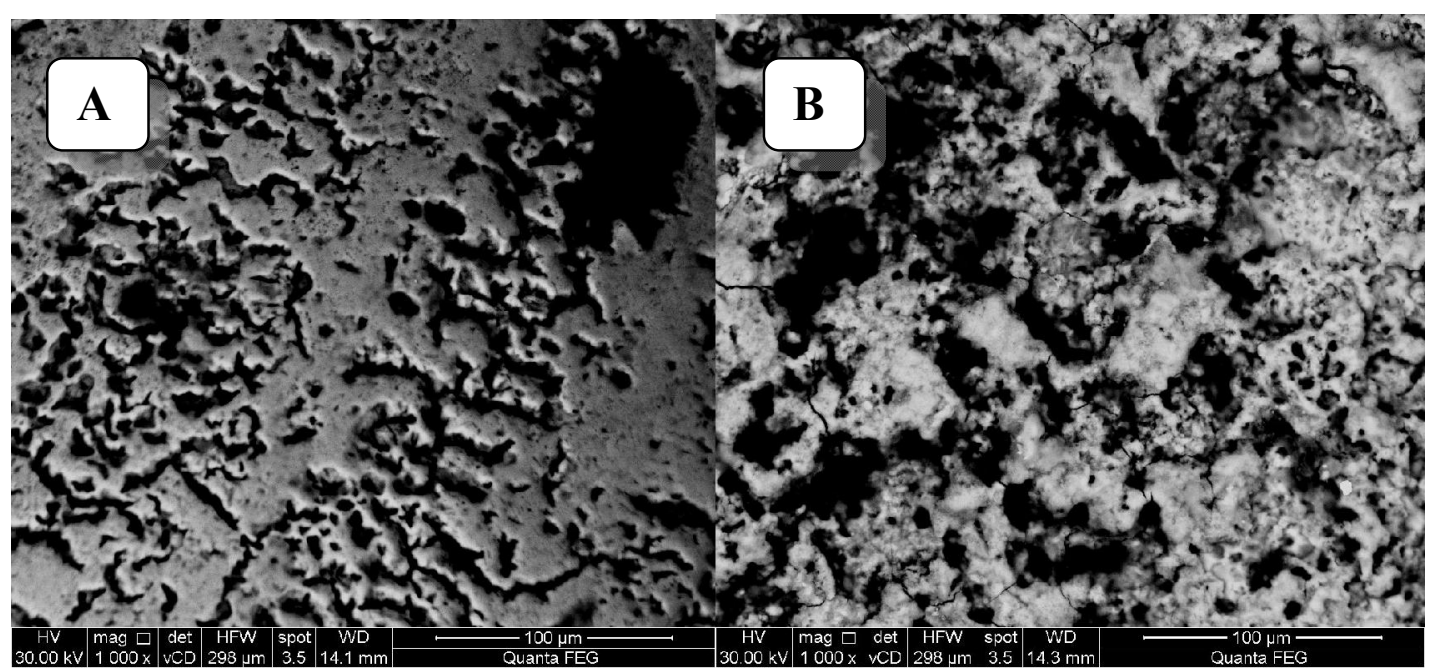

Figure (4) :- (A) ESEM micrograph of demineralized enamel surface (1000x) showing exposure of prismatic enamel and cracked aprismatic enamel. (B) Disoriented enamel crystals.

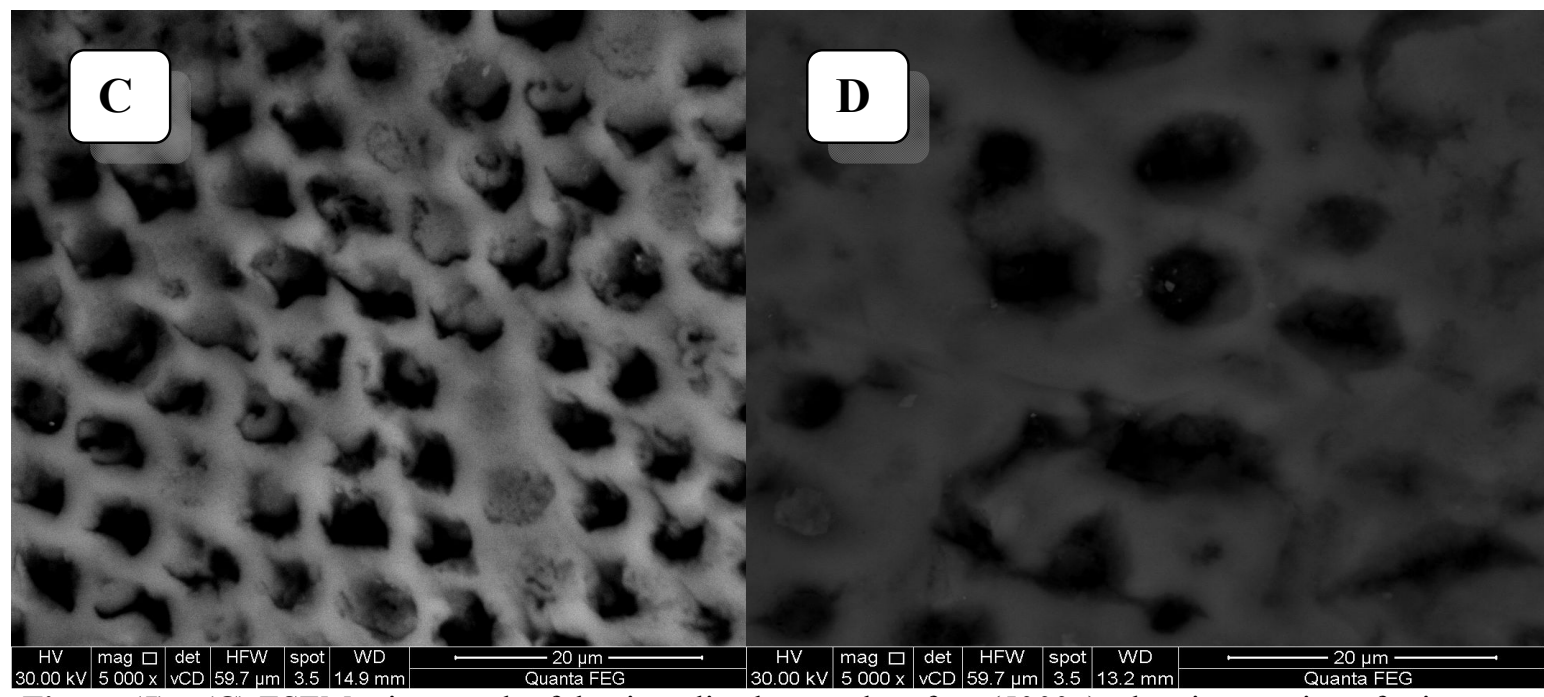

Figure (5):- (C) ESEM micrograph of demineralized enamel surface (5000x): showing erosion of prism cores with preserved prism peripheries with some occluded prisms. (D) (5000x) showing crater shaped cavities. 


\section{Remineralized Enamel:}

\section{Group (1): (Nano Synthetic Apatite): RG1}

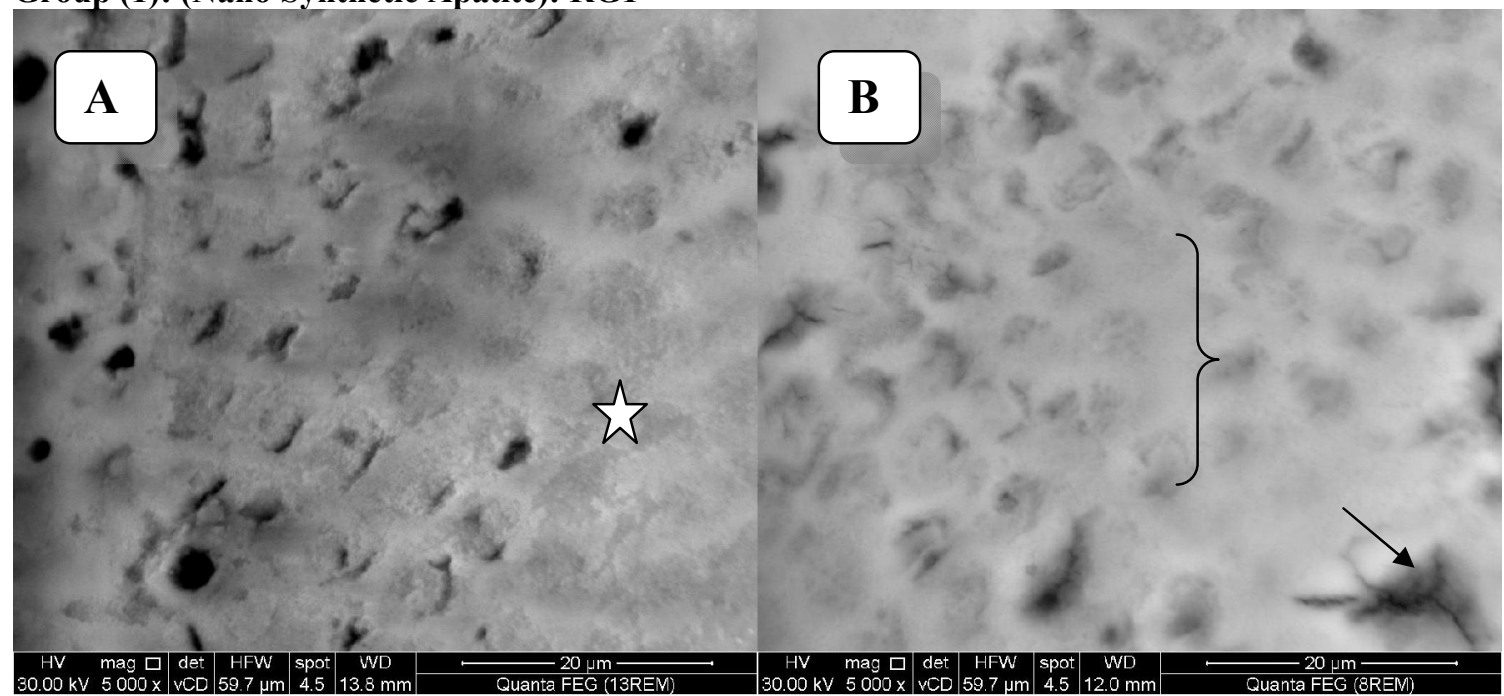

Figure (6):- (A) ESEM micrograph of remineralized enamel surface (5000x) treated with nano-sized synthetic apatite showing a uniform and smooth enamel surface and some prism cores had been completely obliterated and not remarkably visualized (star). (B) (5000x) showing occluded prism cores from the periphery inward (black arrow) and surface uniformity (bracket).

\section{Group (2) (Nano Fluoro Apatite):RG2}

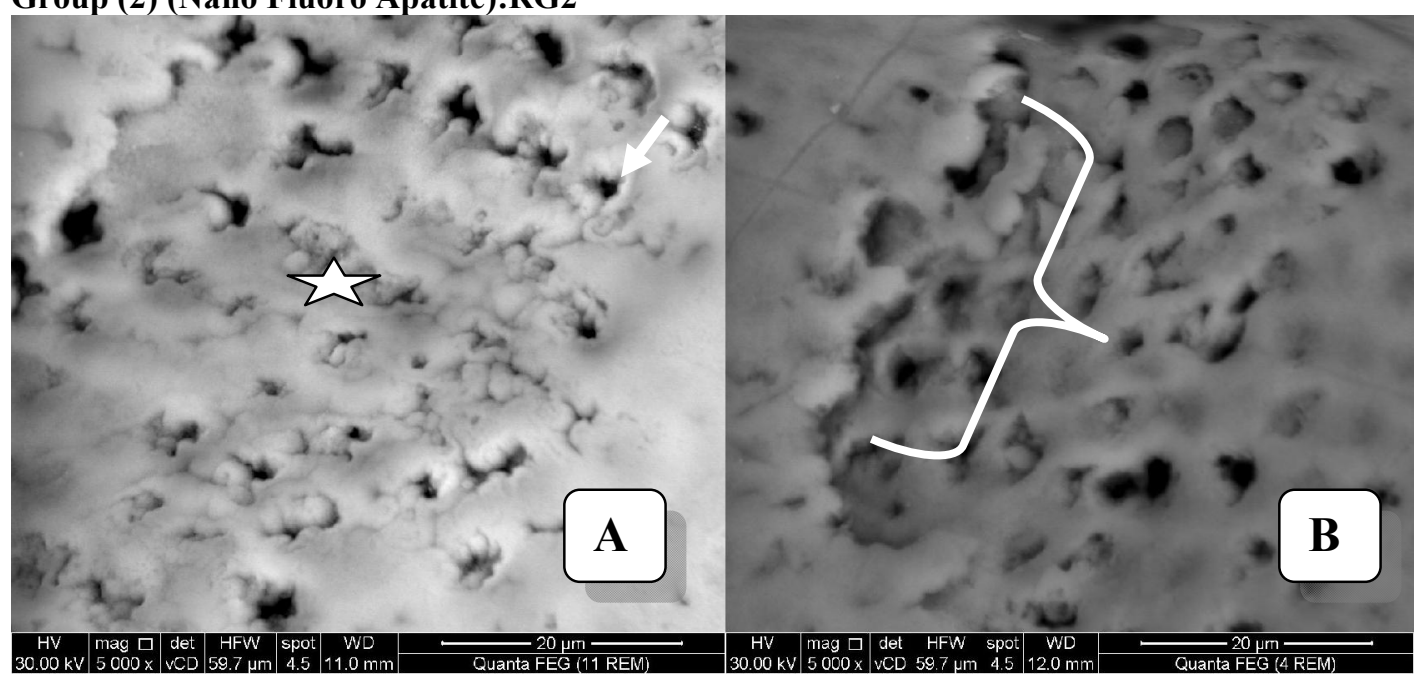

Figure (7): (A): ESEM micrograph of remineralized enamel surface (5000x) treated with nano-sized flouroapatite showing oriental deposition of flouroapatite inside enamel prisms (star) circumscribing the prism periphery and partial narrowing of some prism cores (white arrow) with obvious reduction in the diameter of other cores and some surface deposition in between adjacent prisms. (B) (5000x) showing a uniform and smooth surface with a new layer precipitated over the demineralized enamel obliterating the rod ends (bracket). 


\section{Group (3) (Nano Natural Apatite):RG3}

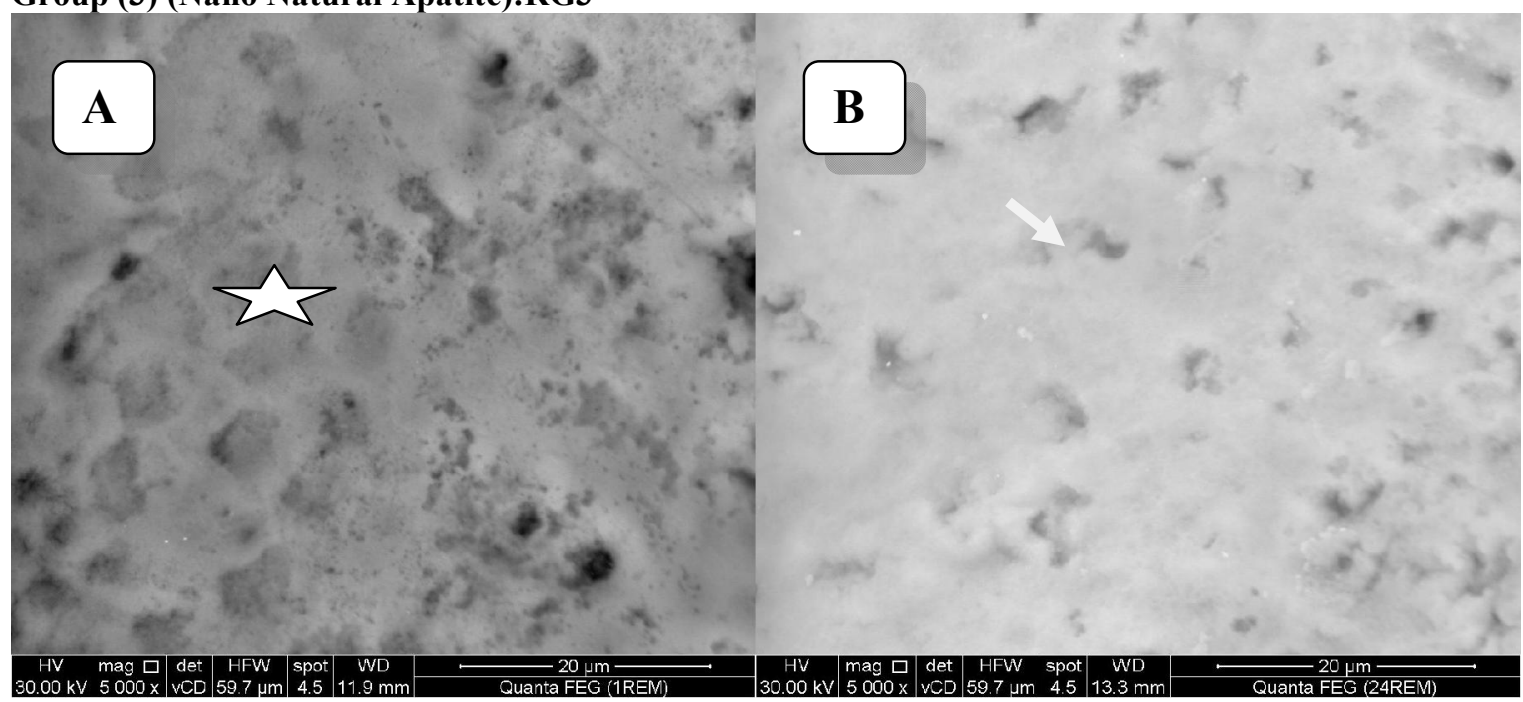

Figure (8) :- (A) ESEM micrograph of remineralized enamel surface (5000x) treated with nano-sized natural apatite showing partial occlusion of some prism cores (star). (B) (5000x) showing complete obliteration of some prism cores (white arrow).

\section{Group (4) (Nano-sized Enamel):RG4}

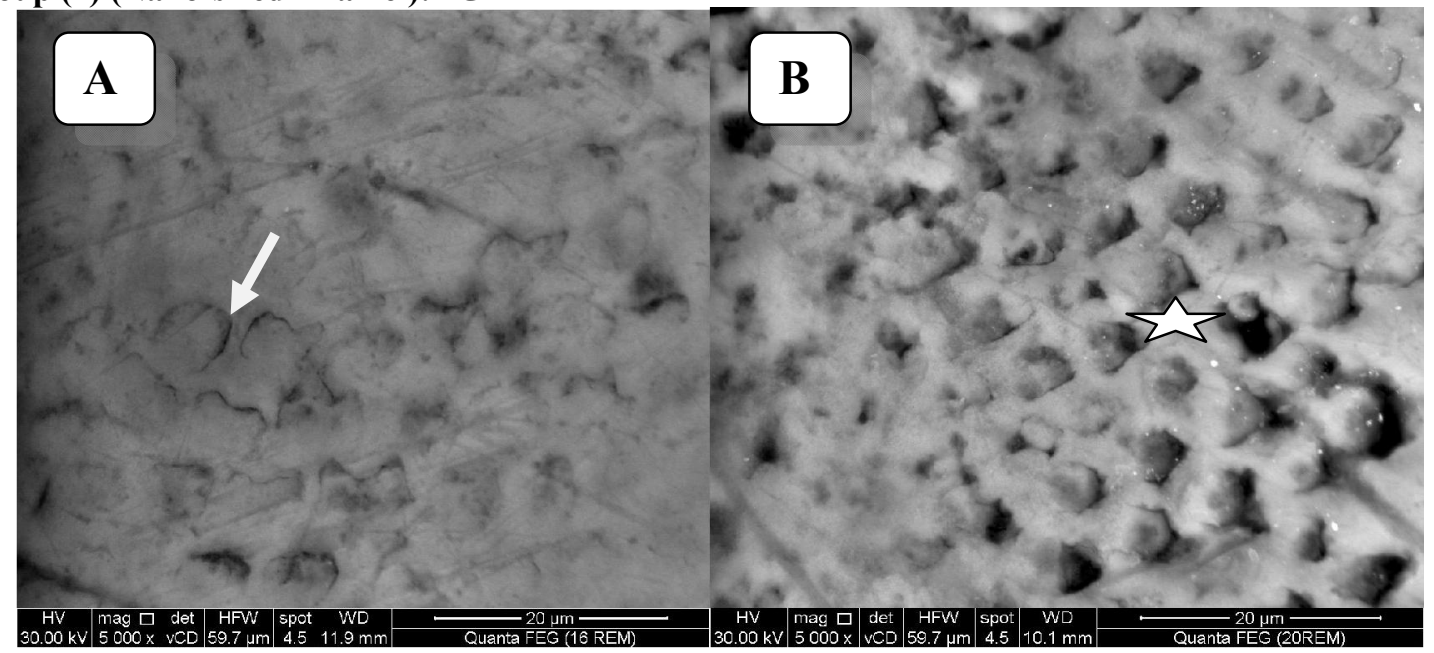

Figure (9):- (A) ESEM micrograph of remineralized enamel surface (5000x) treated with nano-sized enamel showing fish scale appearance similar to untreated enamel (control) (white arrow). (B) (5000x) showing partial occlusion and complete obliteration of prism cores (star).

\section{References:-}

1. Abou Neel Ensanya Ali, Anas Aljabo A, Adam Strange, SalwaI brahim, Melanie Coathup, Anne M.Young,Laurent Bozec and Vivek Mudera:Demineralization -Remineralization Dynamics in Teeth and Bone,International Journal of Nanomedicine, 2016.vol.11,p.4743-4763.

2. Bath-Balogh B., Fehrenbach M.J. and Thomas P.: Illustrated Dental Embryology, Histology and Anatomy, 2nd edition Philadelphia: Saunders2006, p.285-292.

3. Bennett T .Amaechi: Remineralization Therapies for Initial Caries Lesions. Curr Oral Health Rep, 2015.

4. BhusariChitra P. and DivyaS.Sharma: Pattern of Hydroxyapatite Crystal Growth on Bleached Enamel Following the Application of Two Antioxidants: An Atomic Force Microscope Study.The Journal of Clinical Pediatric Dentistry, 2017vol.41. 
5. Browning W.D., Cho S.D. and Deschepper E.J.: Effect of a Nanohydroxyapatite Paste on Bleaching-Related Tooth Sensitivity.Journal of Esthetic and Restorative Dentistry2012., vol.24 (4) p.268-276.

6. CarnerioFlavia Cohen, AlineMaquinePascareli, Marcella Rodrigues, CarneiroChristino, Hugo Felipe Do Vale and Danielson GuedesPontes: Color Stability of Carious Incipient Lesions in Enamel and Treated with Resin Infiltration or Remineralization.International Journal of Pediatric Dentistry, 2013.

7. CeciMatteo, MariaMiranda, Riccardo Beltrami, Marco Chiesa and Claudio Poggio: Protective Effect of Casein Phosphopeptide-amorphous Calcuim Phosphate on Enamel Erosion: Atomic Force Microscopy Studies. Scanning 2015vol.1999, p.1-8.

8. CoceskaEmilija, Elizabeth Gjorgievska, NicholaJ.Coleman, DraganaGabric, Ian J.Slipper, MarijaStevanovic and John W.Nicholson: Enamel Alteration Following Tooth Bleaching and Remineralization.Journal of Microscopy 2015vol.3, p.1-13.

9. ComarLivia P., Beatriz M. Souza, Luiz Fernando Gracindo, Marilia A.R.Buzalaf and Ana Carolina Magalhaes: Impact of Experimental Nano-HAP Pastes on Bovine Enamel and Dentine Submitted to Ph Cycling Model. Brazilian Dental Journal, 2013 24(3) p.273-278.

10. Cury J.A. and TenutaL.M.A: How to maintain a CariostaticFlouride Concentration in the Oral Environment .Advances in Dental Research Journal, 2008vol.20 (1) p.6-13.

11. Da Silva J.D., Park S.E., Weber H.P. and Ishikawa -Nagai S.: Clinical Performance of A Newly Developed Spectrophotometric System on Tooth Color Reproduction.J. Prosthetic Dentistry, 2008vol.99 (5):p.361-368.

12. Denwar Mona El sayedTaha, Amr Ali El SayedNegm, Rehab RezkAbas El Zehary,LobnaR.S.Radwan and Yousry M. Ali Elhawary: Impact of Topically Applied PEPSI drink on Enamel and Dentin Surfaces with and without Application of "Casein Phosphopeptide-Amorphous Calcuim Phosphate with Flouride".Mansoura Journal of Dentistry, 2014.vol 1 (3),p:90-95,

13. Galil K.A. and Wright G.Z.: Acid Etching Patterns on Buccal Surfaces of Permanent Teeth. J. of Pediatric Dentistry, 1979.vol.1(4) p.230-234,

14. Gorseta Kristina, VensaAmbarkova, Tomislav Skrinjaric and DomagojGlavina: Influences of Dentifrices ph on Enamel Microhardness In Vitro.Coll. Antropol. 2015. Vol.39 (2) p.427-431.

15. Haghgoo R., Ahmadvand M., Moshaverinia S.: Remineralizing Effect of Topical NovaMin and Nanohydroxyapatite on caries-like Lesions in Primary teeth. J Contemp Dent Pract. 2016.1; 17(8):645-649.

16. Hannig M. and Hannig C.: Nanomaterials in Preventive Dentistry.Nature Nanotechnology, 2010vol.5.

17. Hannig M. and Hannig C.: Nanotechnology and Its Role in Caries Therapy.Adv.Dent.Res.2012vol.24 (2) p5357.

18. Hayashi Oki, Toshie Chiba, Shinji Shimoda and Yasuko Momoi: Demineralization and Remineralization Phenomena of Human Enamel in Acid Erosion Model.Journal of Hard Tissue Biology, 2016.25(1) p.27-34.

19. Huang S., Gao S., Cheng L., and Yu H.:Remineralization Potential of Nanohydroxyapatite on Initial Enamel Lesions:An in Vitro Study.J.Caries Research, 2011.vol.45p.460-468,

20. Huang S.B., Gao S.S. and Yu H.Y.: Effect of Nanohydroxyapatite Concentration on Remineralization of Initial Enamel Lesions in Vitro.Biomed Mater, 2009vol.4 (3).

21. Jindal S., Gupta N., Gupta P., Arora V. and Mehta N.: Reverse the Adverse: A Review .Int. J. of Adv. Health Sci2015., vol.1 (10).

22. Kielbassa A.M., Muller J. and Grenhardt C.R.: Closing the Gap Between Oral Hygiene and Minimally Invasive Dentistry: A Review on Resin Infiltration Technique of Incipient Enamel Lesions.Quintessence Int. J. 2009.vol.40 (8) p.663-81.

23. Kim J.H., Lee Y.K., Lim B.S., Rhee S.H. and Yang H.C. Effect of Tooth Whitening Strips and Films on Changes in Color and Surface Roughness of Resin Composites.J. Clin.OralInvest. 2004.vol.8 (3) p.118-122.

24. Kim - pusateris, Brewer J.D., Davis E. and Wee A.G.: Reliability and Accuracy of Four Dental Shade Matching Devices.J.Prosthetic Dentistry, 2005 vol.101 (3):p193-199.

25. Kim Y, SonHo, YiK. KimHae, AhnJ.and Chang J.: The Color Change in Artificial White Spot Lesions Measured Using a Spectroradiometer.J.Clin.Oral Invest., 2012.

26. Lu Xiaoying, FanYongbin, GuDachun and Cui Wei: Preparation and Characterization of Natural Hydroxyapatite from Animal Hard Tissues. Key Engineering Materials, 2007vol.342-343, p.213-216.

27. Machale P.S., Hegde-Shetiya S. and Agarwal D..: The Incipient Caries .Journal of Contemporary Dentistry.2013vol.3 (1) p.20-24.

28. MajithiaUdita, KarthikVenkataraghavan, PrashantChoudhary, Krishna Trivedi, Shalin Shah and Mira Virda: Comparative Evaluation of Application of Different Flouride Varnishes on Artificial Early Enamel Lesions: An in Vitro Study, Indian Journal of Dental Research, 2016vol.27p.521-527. 
29. Mielczarek A. and Michalik J.: The Effect of Nanohydroxyapatite Toothpastes on Enamel Surface Remineralization.An in Vitro Study.Am .J. Dent, 2014vol.27:p.287-290.

30. MohantyPritam, SrideviPadmanabhan and Arun B. Chitharanjan: An in Vitro Evaluation of Remineralization Potential of Novamin on Artificial Enamel Sub-surface Lesions Around Orthodontic Brackets Using Energy Dispersive X-Ray Analysis (EDX).Journal of Clinical and Diagnostic Research, 2014vol.8 (11).

31. Nakashima S, Yoshie M, Sano H, Bahar A: Effect of a test dentifrice containing nano-sized calcium carbonate on remineralization of enamel lesions in vitro. J Oral Sci200951:69-7.

32. Okubo S.R., Kanawati A., Richards M.W. and Chidress S.: Evaluation of Visual Instrument Shade Matching.J. of Prosthetic Dentistry, 1998.vol.80(6):p642-648,

33. Patil N., Choudhari S., Kulkarni S. and Joshi S.R.:Comparative Evaluation of Remineralizing Potential of Three Agents on Artificially Demineralized Human Enamel ,An in Vitro Study.J.of Conservative Dentistry, 2013.vol.16(2)p.116-20,

34. Reynolds E.C., Cai F., Cochrane N.J., Shen P., Walker G.D. and Morgan M.V.: Flouride and Casein Phosphopeptide Amorphous CalcuimPhosphate.J.Dent.Res. 2008 vol 87 p.334-348.

35. Roveri N., Battistella E. and Bianchi C.L.: Surface Enamel Remineralization: Biometric Apatite Nanocrystals and Flouride Ions Different Effects.J.Nanomaterials, 2009.

36. Rowe R.C., P.J. Sheskey and S.N.C.Owen: Handbook of Pharmaceutical Excipients.London, Chicago Pharmaceutical Press, 2009.

37. Sandeep Thakur, DevadigaDarshana and HegdeN.Mithra: Comparative Evaluation of the Effect of Various Remineralizing Agents on Bleached Enamel Surface: An in vitro Study.Journal of Pharmaceutical and Scientific Innovation, 2015vol.4 (6).

38. SelivanyBaharJaafar and Fadi Al-Hano: The Effect of Remineralizing Toothpastes on Enamel Surface Roughness after Hybrid Laser Bleaching (An in Vitro Study) 2015.vol.27(4),

39. ShettyShishir, Mithra N Hegde and Thimmaiah P. Bopanna: EnamelRemineraization Assessment after Treatment with Three Different Remineralizing Agents Using Surface Microhardness (An in Vitro Study).Journal of Conservative Dentistry, 2014vol.17 (1).

40. Silverstone L.M., Saxton C.A., Dogon I.L. and Feierskov O.: Variation in Pattern of Acid Etching of Human Dental Enamel Examined by SEM.Caries Research Journal. 1975vol.9p.373-387,.

41. Singh Sombir, Satinder Pal Singh, AshimaGoyal, Ashok Kumar Utreja and Ashok Kumar Jena: Effects of Various Remineralizing Agents on the Outcome of Post-Orthodontic White Spot Lesions: A Clinical Trial.Progress in Orthodontics 2016vol.17 (25).

42. Tencate J.M. and Duijsters P.E.: Altering Demineralization anfRemineralization of Artificial Enamel Lesions .Caries Res.J. 1982vol.16 (3) p.201-10.

43. Tencate J.M., Larsen M.J., Pearce E.I.F. and Fejerskov O.: Chemical Interactions Between the Tooth and Oral Fluids.In: Fejerskov O., Kidd E (ed).Dental Caries -The Disease and its Clinical Management. $2^{\text {nd }}$ ed.Oxford: Blackwell Munksgaard. 2008. ch.12.p.209-32.

44. Tschoppe P., Zandim D.L., Martus P. and Kielbass A.M.: Enamel and Dentin Remineralization by Nanohydroxyapatite toothpastes.J.Dent2011.vol.39p430-437.

45. Tyagi S.P., Paridhi G., Dakshita J.S. and Singh u.p.: An Update on RemineralizingAgents.J.of Interdisciplinary Dentistry, 2013 vol.3(3).

46. Vick V.C.,Goldie M.P. and Shay K.:PatientAssessementIn:Daniel S.J., HarfstS.A.,WilderR.S.Mosby's Dental Hygiene Concepts ,Cases and Competencies. $2^{\text {nd }}$ ed.St.Louis,Mo:Elsevier Mosby2007.p.350,.

47. Wu Duo, JiaojiaoYang, Jiyao Li, Liang Chen, Bei Tang, Xingyu Chen, Wei Wu and JianshuLi: HydroxyapatiteAnchoredDendrimer for in Situ Remineralization of Human Tooth Enamel.Biomaterials, 2013, vol.34p.50365047.

48. Xiang Ge, Yang 1., Chongyum B., Sherry L., Renke W. and Fuzeng R.: Antibacterial coatings of fluoridated hydroxyapatite for percutaneous implants.J.Biomed.Mat. Res. 2010, Vol, 95(A) 2p.588-599.

49. Zhang Xu,YanqiuLi,Xiaoxi Sun, Anil Kishen, Xuliang Deng, Xiaoping Yang,HuajunWang,Changhong Cong, Yinghui Wang and Mingyao Wu: Biometric Remineralization of Demineralized Enamel Nno-Complexes of Phosphorylated Chitosan and Amorphous CalcuimPhosphate.J.Mater Sci,2014,vol.25p.2619-2628.

50. ZhiQh, Ecm Lo and AcyKwok: An in Vitro Study of Silver and Fluoride Ions on Remineralization of Demineralized Enamel and Dentin.Australian Dental Journal, 2013, vol.58 p.50-56. 